\title{
E2 Regulates Epigenetic Signature on Neuroglobin Enhancer-Promoter in Neuronal Cells
}

OPEN ACCESS

Edited by:

Hansen Wang,

University of Toronto, Canada

Reviewed by:

Luis Miguel Garcia-Segura, Consejo Superior de Investigaciones

Cientificas, Spain

Maria Marino,

Roma Tre University, Italy

${ }^{*}$ Correspondence:

Santina Cutrupi santina.cutrupi@unito.it

Received: 21 March 2016 Accepted: 18 May 2016

Published: 01 June 2016

Citation:

Guglielmotto M, Reineri S, lannello $A$, Ferrero G, Vanzan L, Miano V. Ricci L, Tamagno E, De Bortoli $M$ and Cutrupi S (2016) E2 Regulates Epigenetic Signature on Neuroglobin Enhancer-Promoter in Neuronal Cells. Front. Cell. Neurosci. 10:147. doi: 10.3389/fncel.2016.00147

\begin{abstract}
Michela Guglielmotto ${ }^{1,2}$, Stefania Reineri ${ }^{3,4}$, Andrea lannello ${ }^{3,4}$, Giulio Ferrero ${ }^{3,4,5}$, Ludovica Vanzan ${ }^{3}$, Valentina Miano ${ }^{3,4}$, Laura Ricci ${ }^{3,4}$, Elena Tamagno ${ }^{1,2}$, Michele De Bortoli ${ }^{3,4}$ and Santina Cutrupi ${ }^{3,4 *}$

${ }^{1}$ Neuroscience Institute of the Cavalieri Ottolenghi Foundation (NICO), University of Turin, Turin, Italy, ${ }^{2}$ Department Neurosciences, University of Turin, Turin, Italy, ${ }^{3}$ Center for Molecular Systems Biology, University of Turin, Orbassano, Turin, Italy, ${ }^{4}$ Department of Clinical and Biological Sciences, University of Turin, Orbassano, Turin, Italy, ${ }^{5}$ Department of Computer Science, University of Turin, Turin, Italy
\end{abstract}

Estrogens are neuroprotective factors in several neurological diseases. Neuroglobin (NGB) is one of the estrogen target genes involved in neuroprotection, but little is known about its transcriptional regulation. Estrogen genomic pathway in gene expression regulation is mediated by estrogen receptors (ER $\alpha$ and $E R \beta$ ) that bind to specific regulatory genomic regions. We focused our attention on $17 \beta$-estradiol (E2)-induced NGB expression in human differentiated neuronal cell lines (SK-N-BE and NT-2). Previously, using bioinformatics analysis we identified a putative enhancer in the first intron of NGB locus. Therefore, we observed that E2 increased the enrichment of the H3K4me3 epigenetic marks at the promoter and of the H3K4me1 and H3K27Ac at the intron enhancer. In these NGB regulatory regions, we found estrogen receptor alpha $(E R \alpha)$ binding suggesting that $E R \alpha$ may mediate chromatin remodeling to induce NGB expression upon E2 treatment. Altogether our data show that NGB expression is regulated by $E R \alpha$ binding on genomic regulatory regions supporting hormone therapy applications for the neuroprotection against neurodegenerative diseases.

Keywords: neuroglobin, estrogen receptor, chromatin remodeling, genomic regions, epigenetic regulation

\section{INTRODUCTION}

$17 \beta$-estradiol (E2) has neuroprotective activity in several models of neurodegenerative disorders, such as multiple sclerosis, ischemia, stroke and Alzheimer's disease (AD; Arevalo et al., 2015). E2 genomic signaling is mediated by estrogen receptor alpha $(\mathrm{ER} \alpha)$ and beta $(\mathrm{ER} \beta)$, nuclear transcription factor receptors bound to regulatory genomic regions, known as promoters and enhancers. Furthermore, ERs form transcriptional complexes with several transcription factors and cofactors making long range interactions between promoter and enhancer of target genes (Welboren et al., 2009). ERs co-regulators contain chromatin remodeler factors, such as histone modifications enzymes. Chromatin dynamic, linked to epigenetic modifications, is a molecular mechanism for gene expression activation or repression (Magnani and Lupien, 2014; Heinz et al., 2015).

Epigenetic changes under E2 control have an impact on memory consolidation and energy expenditure in hypothalamus (Zhao et al., 2010; Frick et al., 2011; Frank et al., 2014; 
López and Tena-Sempere, 2015). E2 induces an increased expression of chromatin remodeling enzymes, such as histone deacetylases, demethylases and acetyltransferases (Zhao et al., 2010, 2012). In dorsal hippocampus, E2 regulates histone 3 acetylation on the brain-derived neurotrophic factor (BDNF) promoter (Fortress et al., 2014) and ER $\alpha$, but not ER $\beta$ loss, induces impaired spatial memory in mice (Bean et al., 2014). In hypothalamus, E2 modulates energy homeostasis through several pathways, including transcriptional regulation of key genes in brain metabolism, such as oxytocin receptor, progesterone receptor (Gagnidze et al., 2013), leptin receptor (Bennett et al., 1999; Lindell et al., 2001) and pro-opiomelanocortin (Pelletier et al., 2007).

One target protein that increases upon E2 treatment is Neuroglobin (NGB), an oxygen-binding protein that acts as scavenger of reactive oxygen and nitrogen species. NGB plays a neuroprotective action against oxidative damage, after stroke injury and in $\mathrm{AD}$ models. E2 increases NGB levels in a dose-dependent manner $(1-10 \mathrm{nM})$. This effect is reached in $1 \mathrm{~h}$ treatment and is maintained for $24 \mathrm{~h}$ in human neuroblastoma cell lines and in mouse primary hippocampal neurons. The E2 effect on NGB expression is evident also in primary astrocytes (De Marinis et al., 2011, 2013a). Neuronal hypoxia and cerebral ischemia increase NGB levels that protect against neurodegeneration because NGB silencing induces neuron apoptosis (Greenberg et al., 2008). E2 protects $\mathrm{H}_{2} \mathrm{O}_{2}$-induced apoptosis in neurons (De Marinis et al., 2011). $\mathrm{NGB}$ is overexpressed in early stage of $\mathrm{AD}$ and forms a complex with amyloid- $\beta$ peptide (Sun et al., 2013; Seal et al., 2015).

NGB modulation upon E2 treatment is mediated by $\mathrm{ER} \beta$ as demonstrated in human neuroblastoma cell line (SK-N-BE), in mouse primary hippocampal neurons, mouse astrocytes and several cancer cell lines. ER $\beta$ signaling is mediated by membrane-associated proteins and has an effect on mitochondria as apoptosis protection (De Marinis et al., 2011, 2013b; Fiocchetti et al., 2014, 2015). Although these are well assessed data, the question whether ER $\alpha$ may exert a direct effect on NGB transcription has not been worked out in detail, therefore we addressed this question in the present work using SK-N-BE and NT-2 differentiated cells as neuronal-like in vitro models. The comparison of two cell lines from different origin (SK-N-BE, human neuroblastoma cell lines, and NT-2, human embryonal carcinoma cell line) upon differentiation conditions represented models to study E2-induced NGB transcription regulation and find genomic regulatory regions.

Exploring ENCODE database, we found active histone marks and several transcription factors binding in the first intron of NGB locus of different neuronal cell lines (Cutrupi et al., 2014). Here, we found that E2 induced $\mathrm{ER} \alpha$ binding on NGB locus and remodeled chromatin by changing epigenetic marks. We demonstrated that an intronic enhancer, bound by ER $\alpha$ upon E2 treatment, had active histone marks, suggesting that this intronic enhancer is an important regulatory region in NGB transcription regulation. These data showed a potential mechanism by which E2 may mediate neuroprotective action by NGB against neurotoxic stimuli opening the way to hormone therapy for aging.

\section{MATERIALS AND METHODS}

\section{Cell Lines and Treatments}

SK-N-BE, human neuroblastoma cell line, were maintained in RPMI (Roswell Park Memorial Institute) 1640 medium containing $2 \mathrm{mM}$ glutamine and supplemented with $100 \mathrm{~mL} / \mathrm{L}$ fetal bovine serum, $10 \mathrm{~mL} / \mathrm{L}$ non-essential amino acids, and $10 \mathrm{~mL} / \mathrm{L}$ antibiotic mixture (penicillin-streptomycin amphotericin). For differentiation, $2 \times 10^{6}$ were plated in $75 \mathrm{~cm}^{2}$ culture flasks (Corning Costar, Sigma-Aldrich, U.S.A.) and treated with $10 \mu \mathrm{M}$ retinoic acid (RA) for 10 days.

NT-2 cells, human embryonal carcinoma cell line, were maintained in Dulbecco's modified Eagle's medium (DMEM)/F12 (Sigma-Aldrich, U.S.A.), supplemented with 5\% fetal bovine serum and $1 \%$ antibiotic mixture comprising penicillin-streptomycin-amphotericin, in a humidified atmosphere at $37^{\circ} \mathrm{C}$ with $5 \% \quad \mathrm{CO}_{2}$. For differentiation, $2 \times 10^{6}$ cells were plated in $75 \mathrm{~cm}^{2}$ culture flasks (Corning Costar, Sigma-Aldrich, U.S.A.) and exposed to $10 \mu \mathrm{M}$ RA for 5 weeks. Growth medium was changed three times a week. Cells were then replated and, $48 \mathrm{~h}$ after, mitotic inhibitors cytosine arabinoside $(1 \mu \mathrm{M})$, fluorodeoxyuridine $(10 \mu \mathrm{M})$ and uridine $(10 \mu \mathrm{M})$ were added for 2 weeks to inhibit the division of non-neuronal cells. Experiments were performed 4-5 weeks after cessation of RA treatment. Cells were grown for $24 \mathrm{~h}$ in hormone-deprived medium, obtained from phenol red-free DMEM (31053-028, Life Technologies, U.S.A) supplemented with $5 \%$ charcoal-dextrantreated serum, and were treated with $17 \beta$-estradiol (E2; E2758-1G, Sigma-Aldrich, U.S.A.) at a final concentration of $10 \mathrm{nM}$.

\section{Real Time RT-PCR}

Total RNA was isolated using the TRIzol reagent (Life Technologies, U.S.A.). Five hundred nanograms of total RNA was reverse transcribed using the RETROScript cDNA synthesis kit (Life Technologies, U.S.A.).

Real-time PCR was performed using 7900HT Fast Real Time PCR by Applied Biosystems, the iTaqTM Universal SYBRR Green Supermix (Biorad) a Bio-Rad iQ iCycler detection system with SYBR green fluorophore. A melting curve analysis was made after each run to ensure a single amplified product for every reaction. All reactions were run at least in triplicate for each sample. Primers to study NGB expression were as follows NGB-Forward: 5' -TGGAAGACCTGTCCTCACTG$3^{\prime}$ and NGB-Reverse: 5'-GAGCAGAGACTCACCCACTG-3' (Zhang et al., 2011). Gene expression was normalized using specific amplification of $18 \mathrm{~S}$.

\section{Immunoblot Analysis}

SK-N-BE and NT-2 neuronal cells, treated with the appropriate experimental conditions, were quickly placed on ice and washed 
with ice-cold PBS. Whole-cell extracts were prepared in ice-cold lysing buffer Protein concentration in the supernatant was quantified in triplicate by bicinchoninic acid (BCA) assay. For determination of NGB, $100 \mu \mathrm{g}$ of cells lysates were separated in $15 \%$ gels, transferred onto nitrocellulose, and revealed respectively with antibody anti-NGB (Santa Cruz). Membranes were stripped and incubated with anti-actin antibody. Reactions were developed with enhanced chemiluminescence (ECL) system according with the manufacturer's protocol (Amersham-Pharmacia, Biotech, Italia, Cologno Monzese, Italy). Densitometric analysis was performed by using a software program (Multi-analyst, version 1.1, Bio-Rad Laboratories, Segrate, Italy). NGB signal were normalized to those of corresponding actin, were expressed as arbitrary units of optical density and were means \pm SD of three independent experiments.

\section{Chromatin Immunoprecipitation Assay (ChIP)}

Differentiated SK-N-BE and NT-2 were treated with vehicle or E2 and incubated for $45 \mathrm{~min}$ and $1 \mathrm{~h}$, after which they were treated with $1 \%$ formaldehyde in PBS for $10 \mathrm{~min}$ at room temperature on a platform shaker. The crosslinking reaction was stopped by adding glycine at a final concentration of $125 \mathrm{mM}$. Cells were rinsed twice with cold PBS before harvesting and crosslinked cells were then resuspended in Cell Lysis buffer (5 mM Pipes $\mathrm{pH} 8.0,85 \mathrm{mM} \mathrm{KCl}$ and $0.5 \% \mathrm{NP}-40$ ). After a $10 \mathrm{~min}$ incubation on ice, nuclei were collected by centrifugation and resuspended in Nuclei Lysis buffer $(50 \mathrm{mM}$ Tris- $\mathrm{HCl} \mathrm{pH}$ 8.1, $10 \mathrm{mM}$ EDTA and 1\% SDS). Cell lysates were incubated on ice for $10 \mathrm{~min}$ and then sonicated 10 times for $20 \mathrm{~s}$ at $30 \%$ amplitude (SonoPlus HD2070 sonicator). Small portion of sonicated chromatin $(25 \mu \mathrm{l})$ was used to verify that the average size of DNA fragments was in the range of 250-500 bp. DNA/protein complexes $(30 \mu \mathrm{g})$ were diluted in ImmunoPrecipitation buffer $(0.01 \%$ SDS, $1.1 \%$ Triton X100, $1.2 \mathrm{mM}$ EDTA, $16.7 \mathrm{mM}$ Tris- $\mathrm{HCl} \mathrm{pH} 8.0$ and $167 \mathrm{mM}$ $\mathrm{NaCl})$ to a final volume of $400 \mu \mathrm{l}$. Immunoprecipitations were performed by adding $1 \mu \mathrm{g}$ of antibodies against human ER $\alpha$ H184 and HC20 (Santa Cruz Biotechnology, U.S.A.), H3K4me3 and H3K4me1 (Diagenode, Belgium), H3K27me3 and H3K27Ac (Active Motif, U.S.A) and IgG (Abcam, UK) and then incubating at $4^{\circ} \mathrm{C}$ overnight with rotation. Samples with IgG antibody were run in parallel as negative controls. The following day, $30 \mu \mathrm{l}$ of $50 \%$ Protein A Sepharose ${ }^{\mathrm{TM}} 4$ Fast Flow (GE Healthcare, UK) slurry was added and incubated for $2 \mathrm{~h}$ at $4^{\circ} \mathrm{C}$ to capture the immune complexes. Proteins and DNA nonspecifically associated with the beads were removed by sequentially washing with low-salt buffer $(0.1 \%$ SDS, $1 \%$ Triton X-100, 2 mM EDTA, $20 \mathrm{mM}$ Tris- $\mathrm{HCl} \mathrm{pH} 8.0$ and $150 \mathrm{mM} \mathrm{NaCl})$, high-salt buffer $(0.1 \%$ SDS, $1 \%$ Triton X100, $2 \mathrm{mM}$ EDTA, $20 \mathrm{mM}$ Tris- $\mathrm{HCl}, \mathrm{pH} 8.0$ and $500 \mathrm{mM}$ $\mathrm{NaCl}), \mathrm{LiCl}$ washing buffer $(0.25 \mathrm{M} \mathrm{LiCl} ; 1 \%$ deoxycholate sodium salt, $1 \mathrm{mM}$ EDTA, $10 \mathrm{mM}$ Tris- $\mathrm{HCl} \mathrm{pH} 8.0$ and $1 \%$ NP-40) and twice with Tris-EDTA buffer (10 mM Tris$\mathrm{HCl} \mathrm{pH} \mathrm{8.0,} 1 \mathrm{mM}$ EDTA) at $4^{\circ} \mathrm{C}$ for 5 min each wash.
The immunoprecipitated DNA-protein complexes were eluted from beads with $1 \%$ SDS in $0.1 \mathrm{M} \mathrm{NaHCO}_{3}$. Then the DNA-protein complexes were incubated with $0.2 \mathrm{M} \mathrm{NaCl}$ at $65^{\circ} \mathrm{C}$ overnight followed by proteinase $\mathrm{K}$ digestion for $1 \mathrm{~h}$ at $45^{\circ} \mathrm{C}$ to reverse cross-linking. After protein removal, DNA was purified by phenol/chloroform extraction followed by Et-OH precipitation.

Quantification of ChIP enriched DNA was performed by real-time PCR using iTaq Universal SYBR Green Supermix (Bio-Rad, U.S.A.). The enrichment of target sequences in the immunoprecipitated samples was normalized on input samples ( $1 \%$ of total chromatin used per IP) and expressed as enrichment of specific binding over the control unspecific IgG binding. Custom ChIP primers are: NGB promoter forward: 5'-GAGGCGACCAAATTCAACAC-3', reverse: 5' TGCAGAACGTAACTGACATCG-3'; NGB intronic enhancer forward: 5'-CAGCTTGGATGTAGTGCAGC-3', reverse: 5' TTCAGTTACCCGGTGAGACC-3'; GAPDH (Neg) forward: 5'-TACTAGCGGTTTTACGGGCG-3', reverse: 5'-TCGAACA GGAGGAGCAGAGAGCGA-3'.

\section{Bioinformatic Analysis}

The FANTOM5 datasets (http://fantom.gsc.riken.jp/5/) contains transcription start sites (TSSs) and their expression in human and mouse primary cells, tissues and cell lines using cap analysis of gene expression (CAGE) (Forrest et al., 2014). We searched for NGB and analyzed NGB locus using the Zenbu browser genomic tool (Severin et al., 2014). We selected the transcripts, enriched in NGB TSS and in the first intron, expression. For the evaluation of NGB expression level, the main CAGE peak attributed to the gene (p1@NGB) was considered. For the evaluation of the expression level of the RNAs transcribed at the intronic enhancer of NGB, a window of $100 \mathrm{bp}$ focused on the cluster of CAGE peak (chr14:77,735,777-7,773,587, hg19 genome assembly) was selected. The 20 samples associated with the highest CAGE level were considered.

\section{Statistical Analysis}

Statistics were carried out with the GraphPad Prism version 5.03 for Windows by 1-way ANOVA followed by Bonferroni post hoc test.

\section{RESULTS}

\section{NGB Locus in FANTOM5 Database}

We previously published bioinformatic analysis on NGB locus to identify putative regulatory regions. On this way, we explored a new FANTOM5 database, including CAGE experiments across over 900 human samples (Forrest et al., 2014). We found several transcripts in correspondence of the TSS and in the first intron of NGB gene (Figure 1). The first intronic transcript maps on the enhancer that we have previously predicted (chr14:77,735,96377,736,462; hg19; Cutrupi et al., 2014). The presence of the transcripts in an enhancer indicates a site of non- 


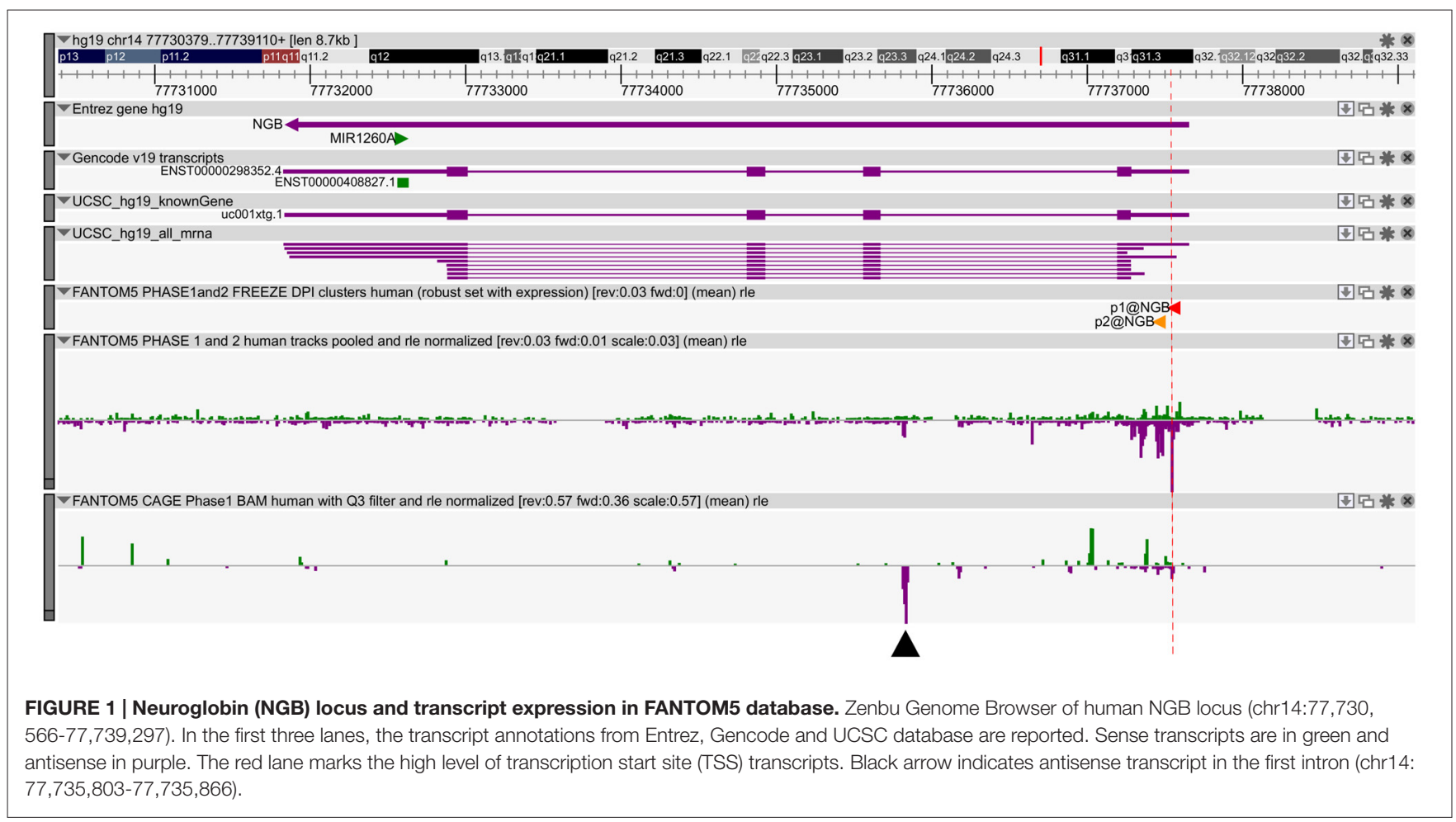

coding RNA transcription and these transcripts may regulate gene expression. Therefore, this region may act as long distance genomic regulatory region for nearby genes (Ong and Corces, 2011). However, the expression data on transcripts stemming from the NGB promoter revealed high abundance in several brain regions, particularly in the locus coeruleus, occipital cortex and lobe, amygdala (Figure 2; NGB promoter CAGE peak). On the contrary, first intronic transcripts are highly expressed in non-neuronal tissues identifying this genomic region (Figure 2; NGB intronic enhancer).

\section{E2 Induces NGB Expression in SK-N-BE and NT-2 Differentiated Cells}

E2-induced NGB protein expression in neuroblastoma cell lines, SK-N-BE, has been previously demonstrated (De Marinis et al., 2011) and, here we investigated SK-N-BE and NT2 cells upon conditions leading to cell differentiation. Cells were plated and cultured in full medium, then maintained in hormone depleted medium for $24 \mathrm{~h}$ before being treated with $10 \mathrm{nM} \mathrm{E2}$ and collected at different time-points (3, 6, 12 and $24 \mathrm{~h}$ ). Cells grown in hormone depleted medium and treated $24 \mathrm{~h}$ with $10 \mathrm{nM}$ Et-OH vehicle were used for comparison. By using quantitative RT-PCR we observed that E2 induced NGB mRNA expression with different kinetic in the two cell types of cells. SK-N-BE cells showed 4fold increase of NGB mRNA after $12 \mathrm{~h}$ of E2 treatment $\left(F_{(4,15)}=7.7, P<0.001\right)$, and NT-2 cells showed NGB mRNA level increase ( $\sim 6$ fold $)$ after $3 \mathrm{~h}$ and is maintained until $12 \mathrm{~h}\left(F_{(4,15)}=44.5, P<0.0001\right.$; Figure 3A). We analyzed NGB protein level using Western blot: NGB protein increased 2-fold after $6 \mathrm{~h}$ of E2 treatment in SK-N-BE cells and 3 -fold after $3 \mathrm{~h}$ in NT-2 cells (Figure $3 \mathrm{~B}$ ). NGB kinetic activation between mRNA and protein upon E2 treatment is different suggesting that E2 may regulate NGB by using multiple mechanisms.

\section{E2 Induces Chromatin Remodeling on NGB Locus in SK-N-BE and NT2 Differentiated Cells}

One step of transcription regulation for gene expression is chromatin remodeling. The dynamic changes of epigenetic modifications are associated with transcription regulation upon E2 treatment (Métivier et al., 2003). Histone marks define the specific states of chromatin: histone 3 lysine 4 trimethylation (H3K4me3) is a marker of active state corresponding to gene transcription activation in the promoter, histone 3 lysine 27 trimethylation $(\mathrm{H} 3 \mathrm{~K} 27 \mathrm{me} 3)$ is a marker of silenced state corresponding to gene transcription silencing, whereas histone 3 lysine 4 monomethylation (H3K4mel) and histone 3 lysine 27 acetylation (H3K27Ac) are markers of active enhancers. E2 induced the enrichment of H3K27Ac in the active enhancer (Hah et al., 2013). To address the underlying molecular mechanisms of how E2 regulates NGB expression we explored histone modifications at the NGB promoter and intronic enhancer using chromatin immunoprecipitation followed by quantitative RT-PCR (ChIP-qPCR). H3K4me3 enrichment was significantly increased on NGB promoter in both cell types after $1 \mathrm{~h}$ of E2 treatment $\left(F_{(2,9)}=11.6, P<0.02\right.$ for SK$\mathrm{N}-\mathrm{BE}$ and $F_{(2,9)}=44.1, P<0.002$ for NT-2; Figure 4A). 
NGB Promoter CAGE peak (p1@NGB)

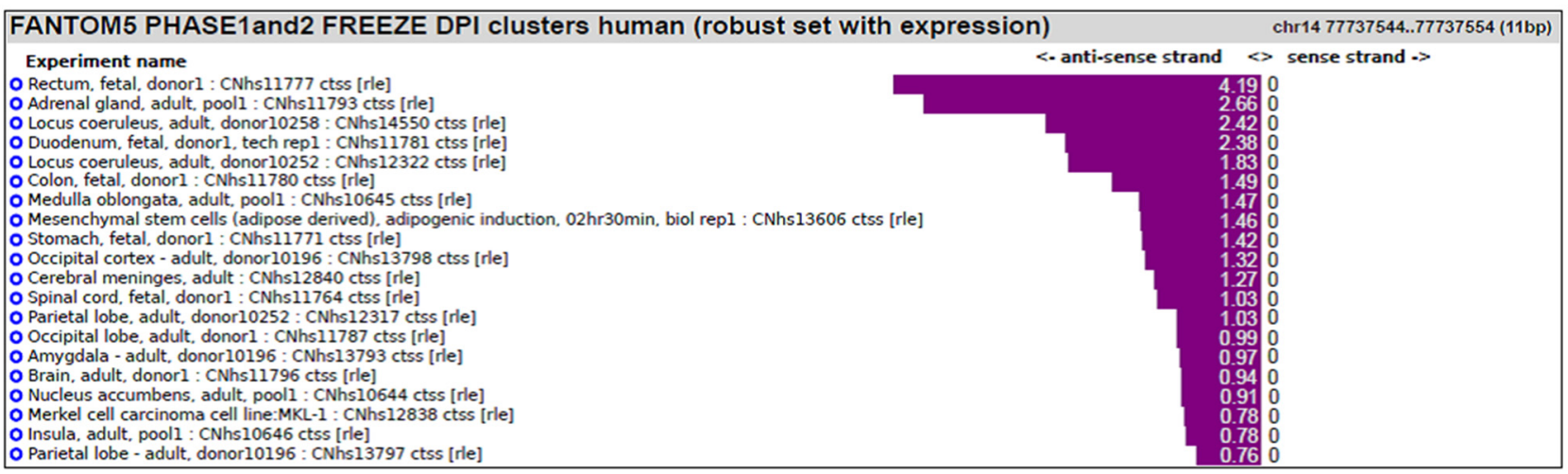

NGB intronic enhancer

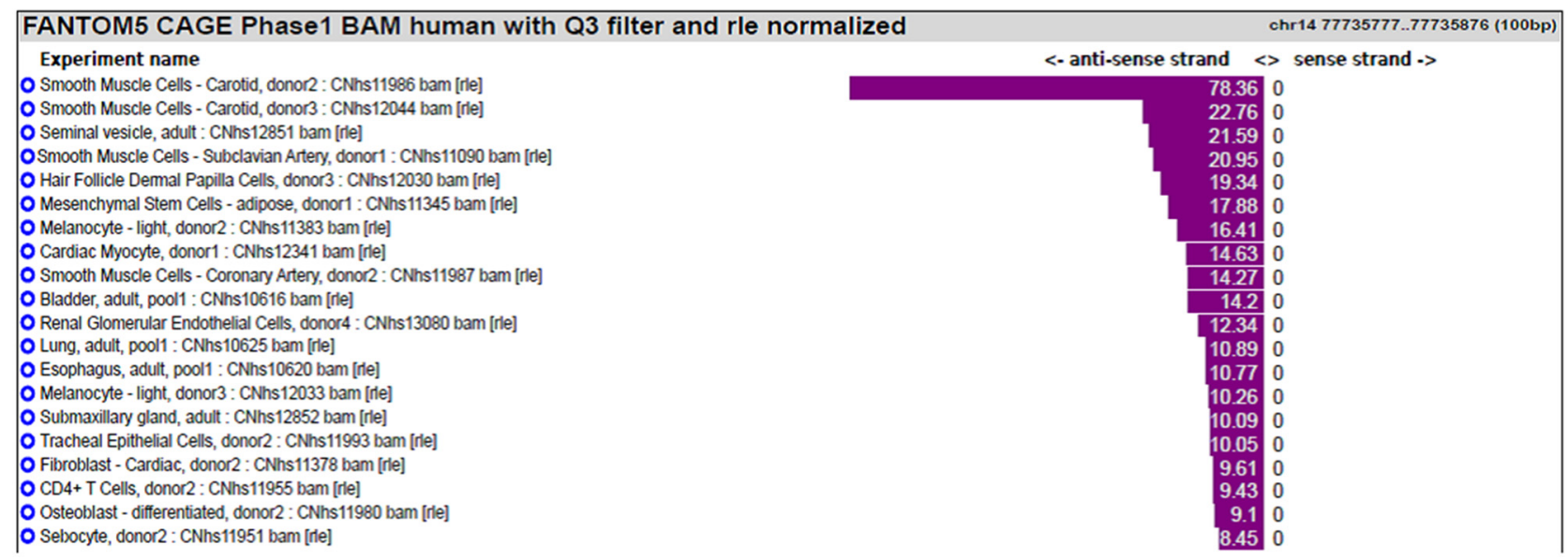

FIGURE 2 | NGB main transcript expression in FANTOM5 database. Bar plot reporting the tissues associated with the highest level of transcripts annotated to the main NGB TSS (p1@NGB) or to the intronic enhancer.

$\mathrm{H} 3 \mathrm{~K} 27 \mathrm{Ac}\left(F_{(2,9)}=71.4, P<0.001\right.$ for SK-N-BE and $F_{(2,9)}=22.3$, $P<0.002$ for NT-2) and H3K4mel $\left(F_{(2,9)}=15.2, P<0.01\right.$ for SK-N-BE and $F_{(2,9)}=62.4, P<0.001$ for NT-2), increased after $45 \mathrm{~min}$ and $1 \mathrm{~h}$ of $\mathrm{E} 2$ treatment in the same manner for the two cell types (Figure 4B). Altogether these data suggest that $\mathrm{E} 2$ may regulate NGB transcription by inducing epigenetic remodeling of NGB promoter and intronic enhancer.

\section{ER $\alpha$ Binds to NGB Promoter and Intronic Enhancer upon E2 Treatment in SK-N-BE and NT-2 Differentiated Cells}

E2 induced histone modifications changes and coexpression of $\mathrm{ER} \alpha$ and $\mathrm{NGB}$ in different brain regions suggest that E2 may regulate NGB expression by $E R \alpha$. To verify whether $\mathrm{ER} \alpha$ binds to NGB promoter and putative enhancer (chr14:77,735,963-77,736,462; hg19; Site B), we performed ChIP-qPCR experiments in SK-N-BE and NT-2 differentiated cells using ER $\alpha$-specific antibodies. E2 induced $\mathrm{ER} \alpha$ binding at NGB promoter and first intron enhancer after $1 \mathrm{~h}$ treatment
(Figure 5). GAPDH promoter was used as negative control for $\mathrm{ER} \alpha$ binding. These data suggest that E2-induced $\mathrm{ER} \alpha$ binding on NGB regulatory regions may recruit co-regulators able to modify chromatin states for NGB transcription activation.

\section{DISCUSSION}

The present study identifies a novel regulatory domain in the first intron of NGB locus acting as enhancer. E2 induced binding of $E R \alpha$ and epigenetic modifications in this genomic region in concert with the promoter. Therefore, we describe ER $\alpha$-mediated genomic pathway able to regulate NGB transcription upon E2 treatment.

$\mathrm{E} 2$ induces $\mathrm{ER} \alpha$ recruitment preferentially to estrogen response element (ERE) regions. In silico analysis revealed the absence of a potential ERE in NGB promoter and intron enhancer. Sp1 and NF-kB transcription factor binding sites are present on NGB promoter and their binding is demonstrated in neuroblastoma cell lines (Liu et al., 2012). Therefore, ER $\alpha$ binding may be mediated by $\mathrm{Sp} 1$ and NF- 


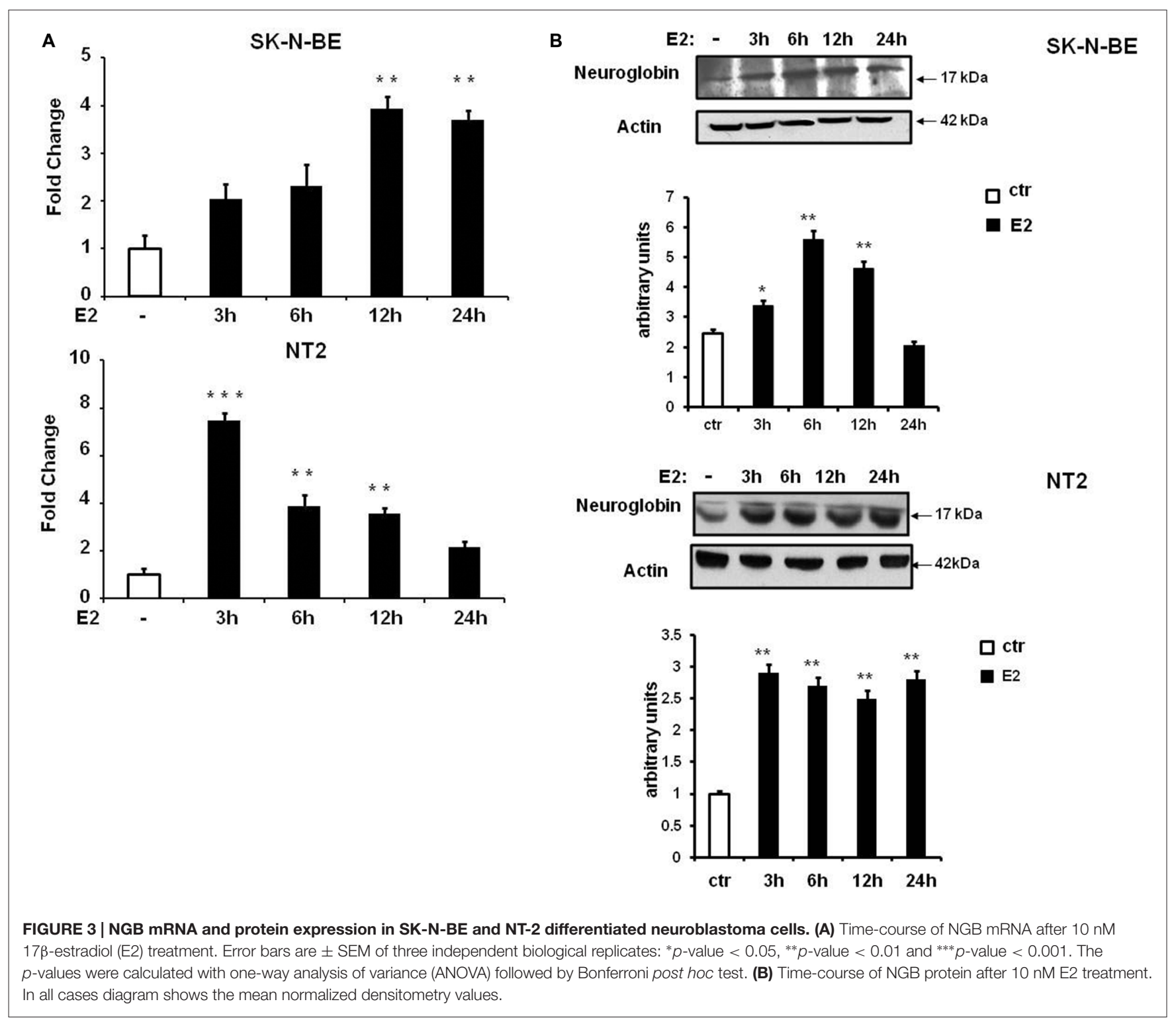

$\mathrm{kB}$ (Welboren et al., 2009). Another transcription factor that mediates $\mathrm{ER} \alpha$ binding is cAMP response element-binding protein (CREB), bound on mouse NGB promoter in N2a neuroblastoma cells (Liu et al., 2013). Exploring the ENCODE database, we found that several transcription factors may bind the NGB intronic enhancer supporting the hypothesis that an active transcriptional complex associated with the intronic enhancer may form an interaction loop with NGB promoter (Cutrupi et al., 2014). The FANTOM5 database showed that the first intron transcripts corresponded to predictive intronic enhancer. CAGE tags identify bidirectional capped RNAs that are overlapped with active histone marks for enhancers, H3K27Ac (Andersson et al., 2014). However, these first intron transcripts are expressed in smooth muscle where NGB expression is not yet detectable suggesting that the first intronic enhancer may be in active state in this specific tissue under basal conditions as a putative alternative
TSS because there is a unidirectional transcript. In neuronal cells, the first intronic enhancer may shift from poised to active state after stimuli. In our neuronal models the intronic enhancer acquires active histone marks upon E2 treatment, even though there are not any transcripts in these specific cell types reported in FANTOM5 library. Therefore, the intronic enhancer may become active after E2 stimulus in neuronal models.

After gene co-expression analysis based on Allen Brain Atlas database (ABA), we found that $E R \alpha$ and $N G B$ are highly co-expressed in hypothalamus (Cutrupi et al., 2014). Using ABA gene expression profiling analysis across specific brain regions, steroid hormone receptors co-expression is associated with cell-types-specific area. In particular, ER $\alpha$ is highly expressed in the specific regions of hypothalamus in according with estrogen-regulated genes, such as NGB (Mahfouz et al., 2016). Estrogen effects in hypothalamic energy homeostasis 


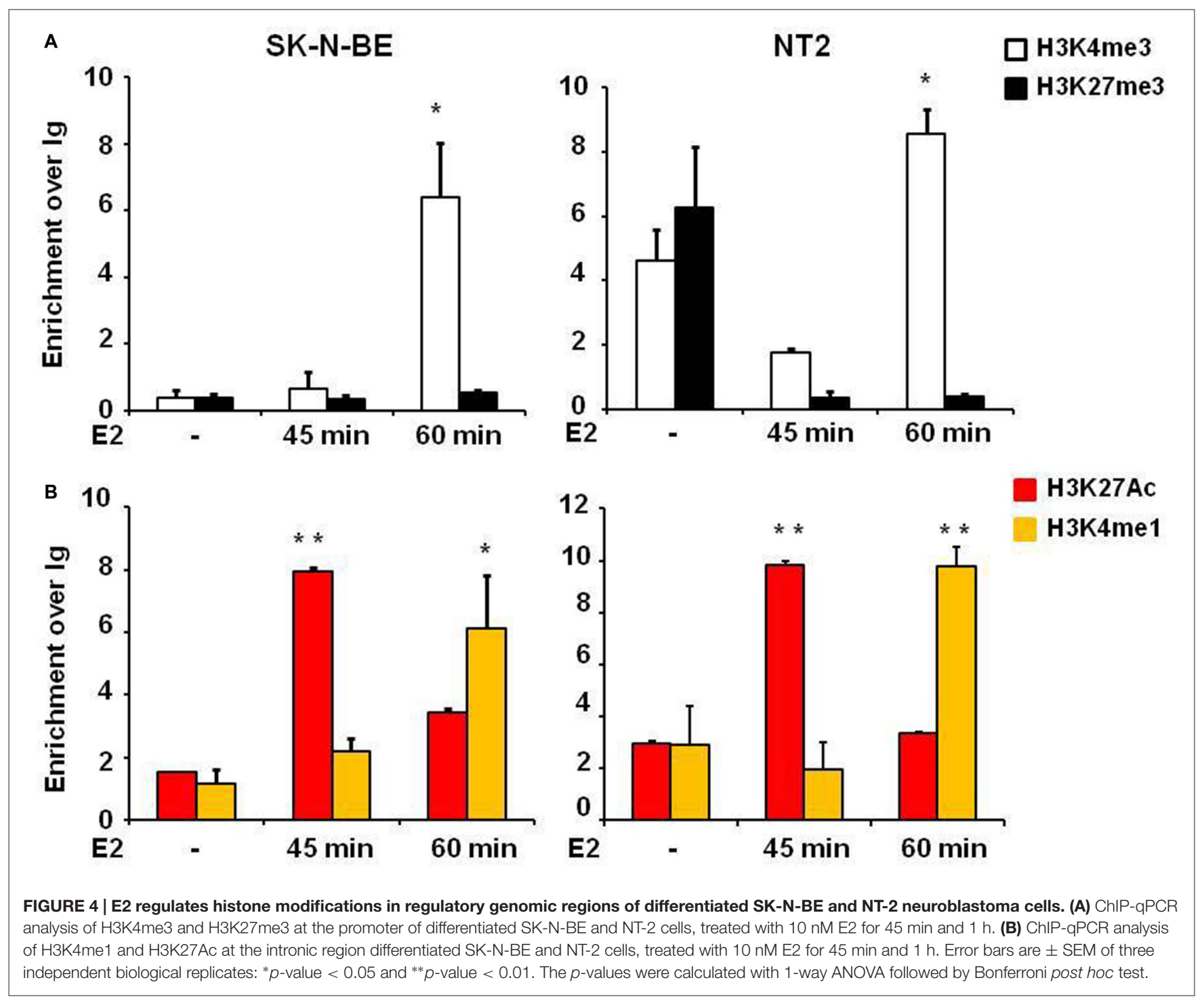

are largely mediated by $\mathrm{ER} \alpha$ as demonstrated by $\mathrm{ER} \alpha$ and ER $\beta$ knock out models (López and Tena-Sempere, 2015). In addition, NGB is also expressed in hippocampus in NGBoverexpressed transgenic mice, under hypoxia and AD (Raida et al., 2013; Sun et al., 2013) and both $\operatorname{ER} \alpha$ and $\operatorname{ER} \beta$ are associated with the same pathological conditions (Arevalo et al., 2015). Altogether these data showed that brain-region-specific molecular mechanisms may regulate NGB expression upon E2 treatment.

E2 regulates NGB expression through both genomic and non-genomic pathways as demonstrated in neuronal and nonneuronal cellular models. E2 enhances NGB protein level in neuronal cells and induces NGB localization in mitochondria where, after oxidative stress injury, NGB inhibits pro-apoptotic signaling by ER $\beta$ (De Marinis et al., 2013b). In mouse cortical astrocytes, ER $\beta$ mediates E2-induced NGB expression and in lipopolysaccharide (LPS)-induced pro-inflammatory signaling (De Marinis et al., 2013a). In cancer cell lines, ER $\alpha$ is overexpressed respect to ER $\beta$ and mediates NGB expression upon E2 treatment (Fiocchetti et al., 2014). In this work we used NT-2 differentiated cells where ER $\alpha$ is over-expressed in respect to $\mathrm{ER} \beta$, therefore $\mathrm{ER} \alpha$ contribution to E2-induced chromatin remodeling at NGB locus may be predominant.

We found that E2 induced ER $\alpha$ binding to NGB promoter and intron enhancer, correlating with the dynamics of epigenetic modifications. E2 induced an increased level of active histone marks $\mathrm{H} 3 \mathrm{~K} 4 \mathrm{me} 3$ at the NGB promoter and $\mathrm{H} 3 \mathrm{~K} 4 \mathrm{me} 1-\mathrm{H} 3 \mathrm{~K} 27 \mathrm{Ac}$ at the intronic enhancer. $\mathrm{ER} \alpha$ is expressed in specific hypothalamus regions that are important in regulating energy homeostasis (Frank et al., 2014). The molecular mechanisms that occur in chromatin remodeling may be an ER $\alpha$-induced recruitment of co-regulators with enzymatic activity to induce histone modifications at the regulatory regions (Green and Carroll, 2007). Several factors are described to form ER $\alpha$ complexes in breast cancer models, but little is known in nervous system. SRC-1 and SRC-2 cofactors, associated with histone acetyltransferase p300/CBP are expressed in specific hypothalamic neurons 


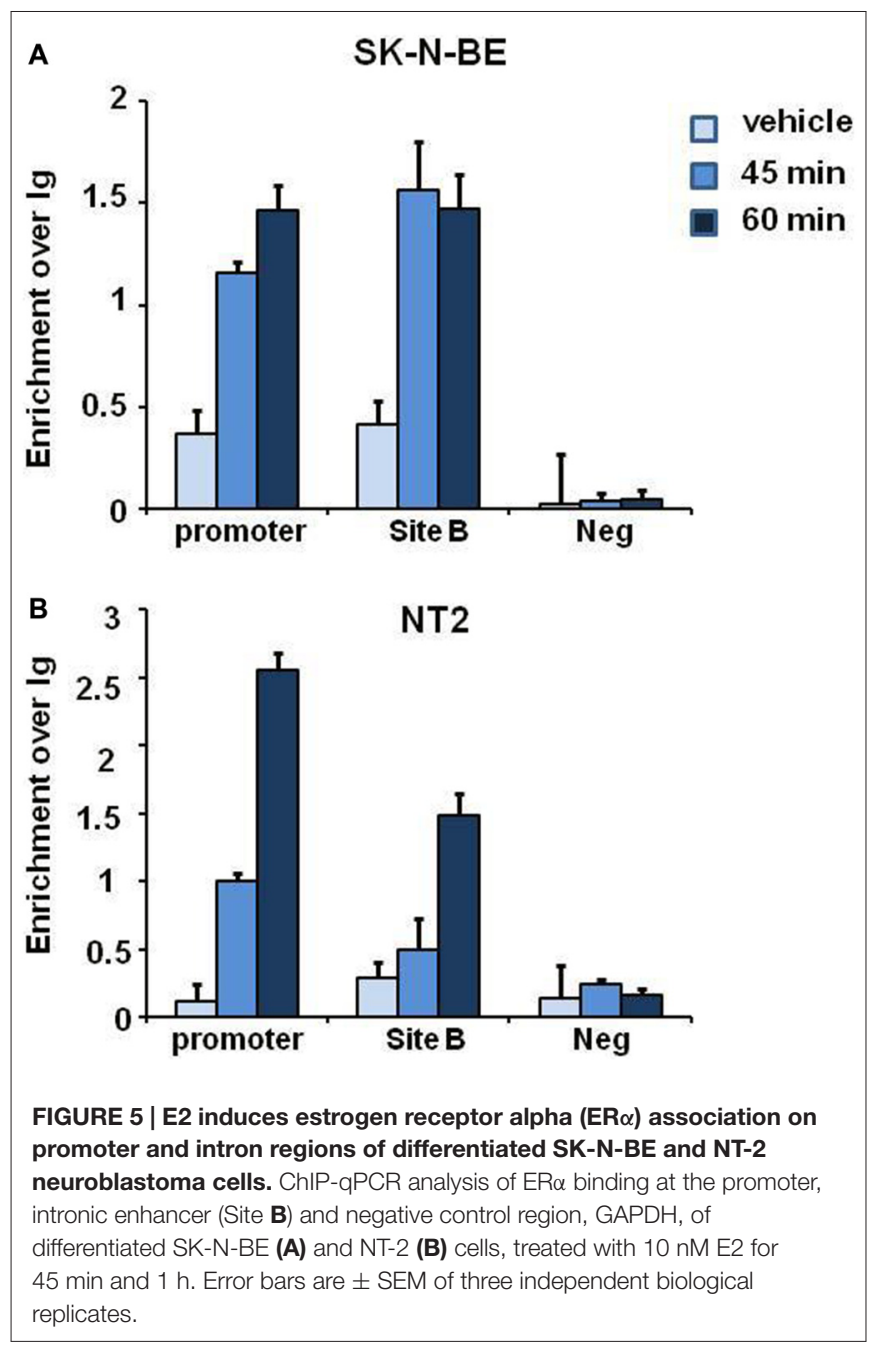

and regulated progesterone receptor expression isoforms (Apostolakis et al., 2002; Gagnidze et al., 2013; Acharya et al., 2015).

In addition, E2 regulated the expression of enzymes that carry out histone modifications: increased histone 3 acetylation and decreased histone deacetylase, HDAC2 and HDAC3, in hippocampus (Frick, 2015). In memory consolidation, histone modifications changes are described on BDNF (Fortress et al., 2014). In this context, E2induced memory effects are mediated by non-genomic pathway where ERK and PI-3 Kinase activated CREB, which represents the transcription factor driving chromatin remodeling and regulation of gene expression (Frick, 2015).

In pathological conditions, E2-induced NGB may mediate an anti-apoptotic response (De Marinis et al., 2011). The decreased levels of E2 during menopause are associated with high risk of cognitive impairment, stroke and $\mathrm{AD}$. E2 has a neuroprotective effect in several animal models of neurodegenerative diseases, such as ischemia, $\mathrm{AD}$ and experimental autoimmune encephalomyelitis (EAE; Arevalo et al., 2015). In addition, $\mathrm{ER} \alpha$ interaction with neurofibrillary tangle and NGB-A $\beta$ complexes suggest that proteins aggregates with $\mathrm{ER} \alpha$ and NGB may inhibit their functions, therefore de-regulation impairs neuroprotective effect in AD (Sun et al., 2013; Seal et al., 2015; Wang et al., 2016). NGB is co-expressed with $\mathrm{ER} \alpha$ in specific hypothalamic regions (Hundahl et al., 2008; Cutrupi et al., 2014). NGB is a heme-protein with oxidative protection function and forms a complex with cytochrome $\mathrm{c}$ in mitochondria ( $\mathrm{Yu}$ et al., 2012). E2 regulated energy homeostasis acting on hypothalamic-specific regions and E2 decline during aging was associated with body weight increase and fat distribution (Fontana et al., 2015). Altogether, these data suggest that E2-induced NGB may regulate mitochondria function: control of glucose metabolism, ATP generation and neuronal apoptosis.

NGB is also expressed in hippocampus where $\mathrm{ER} \alpha$ functions is important in memory formation, while $\operatorname{ER} \beta$ decreased estrogen-target genes (Han et al., 2013; Cho et al., 2015; Frick, 2015). ER $\alpha$ knock out and ER $\alpha$-overexpressed models demonstrated the central role in the memory function (Foster et al., 2008; Bean et al., 2014). ER $\alpha$ downregulation was associated with memory impairment during aging and menopause period where estrogens decline (Frick, 2015). Estrogens regulated neurogenesis in hippocampus and play a central role in neuroplasticity (Barha and Galea, 2010). Our work points attention on epigenetic modifications in genomic regulatory regions upon estrogen treatment, on the same way of epigenetic changes that occur during aging (Frick et al., 2011). Co-expression of ER $\alpha$ and NGB in several brain regions suggests that they may regulate different signaling important for memory formation in the hippocampus and for energy homeostasis in the hypothalamus. The data obtained for NT-2 and SK-N-BE differentiated cells may suggest that transcriptional complex composition and environment regulate NGB expression upon E2 treatment. Therefore, these data in the cellular models support the further experiments in neurodegenerative mice models to investigate which is the epigenetic context advantageous for hormone therapy.

\section{AUTHOR CONTRIBUTIONS}

MG, SR, AI, LV, GF, VM, LR, ET and MDB contribute to: Substantial contributions to the conception or design of the work; or the acquisition, analysis, or interpretation of data for the work; and drafting the work or revising it critically for important intellectual content; and final approval of the version to be published; and agreement to be accountable for all aspects of the work in ensuring that questions related to the accuracy or integrity of any part of the work are appropriately investigated and resolved.

\section{ACKNOWLEDGMENTS}

Research was supported by Italian MURST (PRIN Grant20109MXHMR_005) and Local University of Torino 2015 Research funding. Veronesi Foundation (MG). 


\section{REFERENCES}

Acharya, K. D., Finkelstein, S. D., Bless, E. P., Nettles, S. A., Mulac-Jericevic, B., Conneely, O. M., et al. (2015). Estradiol preferentially induces progestin receptor-A (PR-A) over PR-B in cells expressing nuclear receptor coactivators in the female mouse hypothalamus. eNeuro 2:ENEURO.0012-15.2015. doi: 10. 1523/ENEURO.0012-15.2015

Andersson, R., Gebhard, C., Miguel-Escalada, I., Hoof, I., Bornholdt, J., Boyd, M., et al. (2014). An atlas of active enhancers across human cell types and tissues. Nature 507, 455-461. doi: 10.1038/nature12787

Apostolakis, E. M., Ramamurphy, M., Zhou, D., Oñate, S., and O’Malley, B. W. (2002). Acute disruption of select steroid receptor coactivators prevents reproductive behavior in rats and unmasks genetic adaptation in knockout mice. Mol. Endocrinol. 16, 1511-1523. doi: 10.1210/me.16.7.1511

Arevalo, M.-A., Azcoitia, I., and Garcia-Segura, L. M. (2015). The neuroprotective actions of oestradiol and oestrogen receptors. Nat. Rev. Neurosci. 16, 17-29. doi: 10.1038/nrn3856

Barha, C. K., and Galea, L. A. M. (2010). In fl uence of different estrogens on neuroplasticity and cognition in the hippocampus. Biochim. Biophys. Acta 1800, 1056-1067. doi: 10.1016/j.bbagen.2010.01.006

Bean, L. A., Ianov, L., and Foster, T. C. (2014). Estrogen receptors, the hippocampus and memory. Neuroscientist 20, 534-545. doi: 10. 1177/1073858413519865

Bennett, P. A., Lindell, K., Wilson, C., Carlsson, L. M., Carlsson, B., and Robinson, I. C. (1999). Cyclical variations in the abundance of leptin receptors, but not in circulating leptin, correlate with NPY expression during the oestrous cycle. Neuroendocrinology 69, 417-423. doi: 10.1159/0000 54444

Cho, J., Yu, N. K., Choi, J. H., Sim, S. E., Kang, S. J., Kwak, C., et al. (2015). Multiple repressive mechanisms in the hippocampus during memory formation. Science 350, 82-87. doi: 10.1126/science.aac7368

Cutrupi, S., Ferrero, G., Reineri, S., Cordero, F., and De Bortoli, M. (2014). Genomic lens on neuroglobin transcription. IUBMB Life 66, 46-51. doi: 10. 1002/iub.1235

De Marinis, E., Acaz-Fonseca, E., Arevalo, M. A., Ascenzi, P., Fiocchetti, M., Marino, M., et al. (2013a). 17 $\beta$-Oestradiol anti-inflammatory effects in primary astrocytes require oestrogen receptor b-mediated neuroglobin up-regulation. J. Neuroendocrinol. 25, 260-270. doi: 10.1111/jne.12007

De Marinis, E., Fiocchetti, M., Acconcia, F., Ascenzi, P., and Marino, M. (2013b). Neuroglobin upregulation induced by $17 \beta$-estradiol sequesters cytocrome $\mathrm{c}$ in the mitochondria preventing $\mathrm{H} 2 \mathrm{O} 2$-induced apoptosis of neuroblastoma cells. Cell Death Dis. 4:e508. doi: 10.1038/cddis.2013.30

De Marinis, E., Ascenzi, P., Pellegrini, M., Galluzzo, P., Bulzomi, P., Arevalo, M. A., et al. (2011). 17 $\beta$-estradiol-a new modulator of neuroglobin levels in neurons: role in neuroprotection against $\mathrm{H} 2 \mathrm{O} 2$-induced toxicity. Neurosignals 18, 223-235. doi: 10.1159/000323906

Fiocchetti, M., Camilli, G., Acconcia, F., Leone, S., Ascenzi, P., and Marino, M. (2015). ER $\beta$-dependent neuroglobin up-regulation impairs $17 \beta$-estradiolinduced apoptosis in DLD-1 colon cancer cells upon oxidative stress injury. J. Steroid Biochem. Mol. Biol. 149, 128-137. doi: 10.1016/j.jsbmb.2015.02.005

Fiocchetti, M., Nuzzo, M. T., Totta, P., Acconcia, F., Ascenzi, P., and Marino, M. (2014). Neuroglobin, a pro-survival player in estrogen receptor $\alpha$-positive cancer cells. Cell Death Dis. 5:e1449. doi: 10.1038/cddis.2014.418

Fontana, R., Della Torre, S. D., Meda, C., Longo, A., Eva, C., and Maggi, A. C. (2015). Estrogen replacement therapy regulation of energy metabolism in female mouse hypothalamus. Endocrinology 155, 2213-2221. doi: 10.1210/en. 2013-1731

Forrest, A. R. R., Kawaji, H., Rehli, M., Baillie, J. K., de Hoon, M. J., Haberle, V., et al. (2014). A promoter-level mammalian expression atlas. Nature 507, 462-470. doi: 10.1038/nature13182

Fortress, A. M., Kim, J., Poole, R. L., Gould, T. J., and Frick, K. M. (2014). 17ßEstradiol regulates histone alterations associated with memory consolidation and increases Bdnf promoter acetylation in middle-aged female mice. Learn. Mem. 21, 457-467. doi: 10.1101/lm.034033.113

Foster, T. C., Rani, A., Kumar, A., Cui, L., and Semple-Rowland, S. L. (2008). Viral vector-mediated delivery of estrogen receptor- $\alpha$ to the hippocampus improves spatial learning in estrogen receptor- $\alpha$ knockout mice. Mol. Ther. 16, 1587-1593. doi: $10.1038 / \mathrm{mt} .2008 .140$
Frank, A., Brown, L. M., and Clegg, D. J. (2014). The role of hypothalamic estrogen receptors in metabolic regulation. Front. Neuroendocrinol. 35, 550-557. doi: 10. 1016/j.yfrne.2014.05.002

Frick, K. M. (2015). Molecular mechanisms underlying the memory-enhancing effects of estradiol. Horm. Behav. 74, 4-18. doi: 10.1016/j.yhbeh.2015. 05.001

Frick, K. M., Zhao, Z., and Fan, L. (2011). The epigenetics of estrogen epigenetic regulation of hormone-induced memory enhancement. Epigenetics 6, 675-680. doi: 10.4161/epi.6.6.16177

Gagnidze, K., Weil, Z. M., Faustino, L. C., Schaafsma, S. M., and Pfaff, D. W. (2013). Early histone modifications in the ventromedial hypothalamus and preoptic area following oestradiol administration. J. Neuroendocrinol. 25, 939-955. doi: 10.1111/jne.12085

Green, K. A., and Carroll, J. S. (2007). Oestrogen-receptor-mediated transcription and the influence of co-factors and chromatin state. Nat. Rev. Cancer 7, 713-722. doi: 10.1038/nrc2211

Greenberg, D. A., Jin, K., and Khan, A. A. (2008). Neuroglobin: an endogenous neuroprotectant. Curr. Opin. Pharmacol. 8, 20-24. doi: 10.1016/j.coph.2007.09. 003

Hah, N., Murakami, S., Nagari, A., Danko, C. G., and Lee Kraus, W. (2013). Enhancer transcripts mark active estrogen receptor binding sites. Genome Res. 23, 1210-1223. doi: 10.1101/gr.152306.112

Han, X., Aenlle, K. K., Bean, L. A., Rani, A., Semple-Rowland, S. L., Kumar, A., et al. (2013). Role of estrogen receptor $\alpha$ and $\beta$ in preserving hippocampal function during aging. J. Neurosci. 33, 2671-2683. doi: 10.1523/JNEUROSCI. 4937-12.2013

Heinz, S., Romanoski, C. E., Benner, C., and Glass, C. K. (2015). The selection and function of cell type-specific enhancers. Nat. Rev. Mol. Cell Biol. 16, 144-154. doi: 10.1038/nrm3949

Hundahl, C. A., Kelsen, J., Dewilde, S., and Hay-Schmidt, A. (2008). Neuroglobin in the rat brain (II): Co-localisation with neurotransmitters. Neuroendocrinology 88, 183-198. doi: 10.1159/000135617

Lindell, K., Bennett, P. A., Itoh, Y., Robinson, I. C. A. F., Carlsson, L. M. S., and Carlsson, B. (2001). Leptin receptor $5^{\prime}$ untranslated regions in the rat: relative abundance, genomic organization and relation to putative response elements. Mol. Cell. Endocrinol. 172, 37-45. doi: 10.1016/s0303-7207(00)00382-8

Liu, N., Yu, Z., Li, Y., Yuan, J., Zhang, J., Xiang, S., et al. (2013). Transcriptional regulation of mouse neuroglobin gene by cyclic AMP responsive element binding protein (CREB) in N2a cells. Neurosci. Lett. 534, 333-337. doi: 10. 1016/j.neulet.2012.11.025

Liu, N., Yu, Z., Xiang, S., Zhao, S., Tjärnlund-Wolf, A., Xing, C., et al. (2012). Transcriptional regulation mechanisms of hypoxia-induced neuroglobin gene expression. Biochem. J. 443, 153-164. doi: 10.1042/BJ20111856

López, M., and Tena-Sempere, M. (2015). Estrogens and the control of energy homeostasis: a brain perspective. Trends Endocrinol. Metab. 26, 411-421. doi: 10.1016/j.tem.2015.06.003

Magnani, L., and Lupien, M. (2014). Chromatin and epigenetic determinants of estrogen receptor $\alpha$ (ESR1) signaling. Mol. Cell. Endocrinol. 382, 633-641. doi: 10.1016/j.mce.2013.04.026

Mahfouz, A., Lelieveldt, B. P. F., Grefhorst, A., Van Weert, L. T. C. M., and Mol, I. M. (2016). Genome-wide coexpression of steroid receptors in the mouse brain: identifying signaling pathways and functionally coordinated regions. Proc. Natl. Acad. Sci. U S A 113, 2738-2743. doi: 10.1073/pnas.1520376113

Métivier, R., Penot, G., Hübner, M. R., Reid, G., Brand, H., Kos, M., et al. (2003). Estrogen receptor- $\alpha$ directs ordered, cyclical and combinatorial recruitment of cofactors on a natural target promoter. Cell 115, 751-763. doi: 10.1016/s00928674(03)00934-6

Ong, C., and Corces, V. (2011). Enhancer function: new insights into the regulation of tissue-specific gene expression. Nat. Rev. Genet. 12, 283-293. doi: $10.1038 / \mathrm{nrg} 2957$

Pelletier, G., Li, S., Luu-The, V., and Labrie, F. (2007). Oestrogenic regulation of pro-opiomelanocortin, neuropeptide $\mathrm{Y}$ and corticotrophin-releasing hormone mRNAs in mouse hypothalamus. J. Neuroendocrinol. 19, 426-431. doi: 10. 1111/j.1365-2826.2007.01548.x

Raida, Z., Hundahl, C. A., Nyengaard, J. R., and Hay-Schmidt, A. (2013). Neuroglobin over expressing mice: expression pattern and effect on brain ischemic infarct size. PLoS One 8:e76565. doi: 10.1371/journal.pone. 0076565 
Seal, M., Uppal, S., Kundu, S., and Dey, S. G. (2015). Interaction of apoNeuroglobin with heme-A $\alpha$ complexes relevant to Alzheimer's disease. J. Biol. Inorg. Chem. 20, 563-574. doi: 10.1007/s00775-015-1241-y

Severin, J., Lizio, M., Harshbarger, J., Kawaji, H., Daub, C. O., Hayashizaki, Y., et al. (2014). Interactive visualization and analysis of large-scale sequencing datasets using ZENBU. Nat. Biotechnol. 32, 217-219. doi: 10.1038/nbt.2840

Sun, F., Mao, X., Xie, L., Greenberg, D. A., and Jin, K. (2013). Neuroglobin protein is upregulated in Alzheimer's disease. J. Alzheimers Dis. 36, 659-663. doi: 10. 3233/JAD-130323

Wang, C., Zhang, F., Jiang, S., Siedlak, S. L., Shen, L., Perry, G., et al. (2016). Estrogen receptor- $\alpha$ is localized to neurofibrillary tangles in Alzheimer's disease. Sci. Rep. 6:20352. doi: 10.1038/srep20352

Welboren, W. J., Sweep, F. C. G. J., Span, P. N., and Stunnenberg, H. G. (2009). Genomic actions of estrogen receptor $\alpha$ : what are the targets and how are they regulated? Endocr. Relat. Cancer 16, 1073-1089. doi: 10.1677/ERC09-0086

Yu, Z., Liu, N., Liu, J., Yang, K., and Wang, X. (2012). Neuroglobin, a novel target for endogenous neuroprotection against stroke and neurodegenerative disorders. Int. J. Mol. Sci. 13, 6995-7014. doi: 10.3390/ijms13066995

Zhang, W., Tian, Z., Sha, S., Cheng, L. Y. L., Philipsen, S., and Tan-Un, K.-C. (2011). Functional and sequence analysis of human neuroglobin gene promoter region. Biochim. Biophys. Acta 1809, 236-244. doi: 10.1016/j.bbagrm.2011. 02.003

Zhao, Z., Fan, L., Fortress, A. M., Boulware, M. I., and Frick, K. M. (2012). Hippocampal histone acetylation regulates object recognition and the estradiolinduced enhancement of object recognition. J. Neurosci. 32, 2344-2351. doi: 10. 1523/JNEUROSCI.5819-11.2012

Zhao, Z., Fan, L., and Frick, K. M. (2010). Epigenetic alterations regulate estradiolinduced enhancement of memory consolidation. Proc. Natl. Acad. Sci. U S A 107, 5605-5610. doi: 10.1073/pnas.0910578107

Conflict of Interest Statement: The authors declare that the research was conducted in the absence of any commercial or financial relationships that could be construed as a potential conflict of interest.

Copyright (C) 2016 Guglielmotto, Reineri, Iannello, Ferrero, Vanzan, Miano, Ricci, Tamagno, De Bortoli and Cutrupi. This is an open-access article distributed under the terms of the Creative Commons Attribution License (CC BY). The use, distribution and reproduction in other forums is permitted, provided the original author(s) or licensor are credited and that the original publication in this journal is cited, in accordance with accepted academic practice. No use, distribution or reproduction is permitted which does not comply with these terms. 